\title{
Die Iuridici Alexandreae.
}

Gelegentlich der Besprechung eines interessanten Bruchstückes aus dem Amtsjournal des Iuridicus Alexandreae Flavius Gennadius stellt Jouguet in dieser Zeitschrift S. $304 \mathrm{f}$. die bisher bekannten Juridici zusammen; da Einzelheiten hinzuzufügen wären, sei nachfolgend versucht, die Liste nochmals zu geben.

Eine Erwähnung dieses Amtes vor Tiberius finden wir nicht. Zum ersten Mal weist darauf hin die Inschrift des

L. Volusenus L.f. Clu(stumina) Clemens, der seine Ämterlaufbahn unter Augustus und Tiberius durchmachte. Er wurde von Tiberius nach Ägypten ad iur(is) dict(ionem) geschickt; doch hat er sein Amt nicht angetreten, da er vor seiner Ankunft in Ägypten starb. ${ }^{1}$ )

2) Umbrius. In der Eingabe der Dionysia wird aus den Tage-

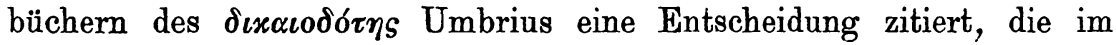
6. Jahr Domitians, im Monat Phamenoth, das ist 25. Febr./26. März 87 n. Chr., erlassen ist (Oxy. II 237 p. 161 Col. VII 39.42 f.).

3) L. Baebius L. f. Gal(eria) Iuncinus. In seinem Cursus honorum (CIL. X 6976) steht an letzter Stelle iuridicus Aegypti ${ }^{2}$ ); er hat dieses Amt nach der Praefectura vehiculorum innegehabt. Der Zeitpunkt seiner Thätigkeit in Ägypten ist nach beiden Seiten abgegrenzt: die Bekleidung seiner militärischen Chargen fällt noch vor oder unter Hadrian, da er noch in der von Hadrian kassierten legio XXII Deiotariana $^{3}$ ) diente, praefectus vehiculorum aber war er als Ritter frühestens unter Hadrian. ${ }^{4}$ )

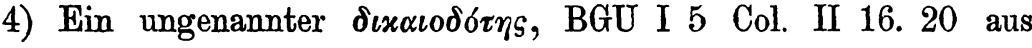
dem Jahre 137/8 n. Chr.

1) CIL. XI $6020=$ Dessau, inscr. Lat. sel. 2691. Zu diesem und den folgenden Männern mag auch die Prosopogr. imp. Rom. verglichen werden.

2) Man wird kaum anzunehmen haben, dals dies etwas anderes ist als der iuridicus Alexandriae, da nirgends eine Spur von einer Unterscheidung der iuridici zu finden ist.

3) Vgl. P. Meyer, Jahrb. f. Phil. CLV (1897) 583.

4) Vgl. Hirschfeld, Verw.-G. 100, 3. 
5) Sex. Cornelius Sex.f. Arn(ensis) Dexter war im jüdischen Krieg Hadrians (132-135 n. Chr.) Befehlshaber der syrischen Flotte; dann kam er nach Alexandria als proc(urator) Neaspoleos et mausolei und blieb gleich hier, als er zum iuridicus Alexandreae befördert wurde. In den ersten Regierungsjahren des Antoninus Pius scheint er in dieser Stellung gewesen zu sein. Sein nächstes Avancement verschaffte ihm die Procuratur von Asia. ${ }^{1}$ )

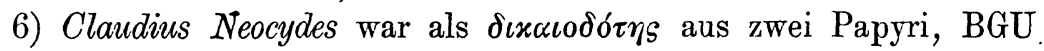
I 245 und II 378, bekannt, die sich zeitlich nicht genau festsetzen liefsen: bei jenem ist die Datierung überhaupt nicht erhalten, bei diesem nur das 10. Jahr eines Kaisers angegeben, dessen Name nicht genannt ist. Die Lösung bot P. Lond. II 152, nr. 196; der hier ge-

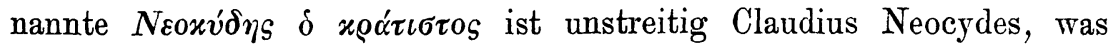
sich auch aus der Wiederkehr des Namens Julius Agrippinus (BGU II 378) in dieser Urkunde ergiebt. Da der Papyrus des britischen Museums der Zeit des Pius angehört, so ist auch der Kaiser, nach dessen 10. Jahr der andere Papyrus (378) datiert ist, Pius. Es ist daher jene Urkunde mit dem April 147 zu datieren. Damals war

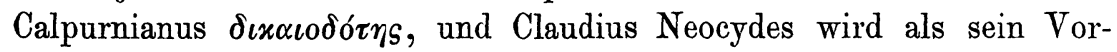
gänger erwähnt. Entscheidungen dieser beiden und des Maximianus sind in dem nicht genauer datierten Papyrus Grenfell und Hunt, Fayûm towns and their papyri (London 1900) 300, nr. 203 enthalten.

7) Maximianus wird durch den nur dem Inhalt nach mitgeteilten Papyrus Fayûm a. a. O. bekannt; er ist zwischen Neocydes und Calpurnianus genannt, seine Amtszeit fällt daher wohl auch zwischen die dieser Beiden.

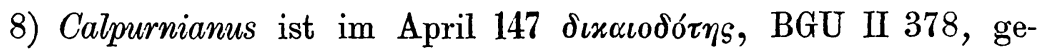
nannt auch Fayûm a. a. O., s. zu Nr. 6.

9) Calvisius Patrophilus ist im folgenden (11.) Jahr (des Pius),

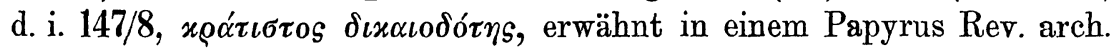
XXIV (1894) 70, wird also Calpurnianụs' unmittelbarer Nachfolger gewesen sein.

10) ...... itius C.f. .... CIL. VI $1564=$ Dessau 1452 ; vgl. Prosopogr. imp. Rom. III 501; 50. Die Ergänzung [Quint]ilius beruht auf der unsichern Vermutung, dafs an der Fundstelle der Inschrift die Villa der Quintilier gelegen habe. ${ }^{2}$ ) Auch auf [C. Caec]ilius [Salvianus]

1) CIL. VIII 8925. $8934=$ Dessau, inscr. 1400; vgl. auch Pauly-Wissowa, Realencyklopädie s. v.

2) Über eine andere Villa der Quintilier vgl. F. Grossi-Gondi, Bull. com. 1898, 313-338. 
(nr. 13) wird kaum zu raten sein. Bevor er iuridicus Alexandreae wurde, war er in irgend einer (aber nicht in leitender) Stellung beim lateinischen Sekretariat am kaiserlichen $\mathrm{Hofe}_{\text {beschäftigt }}{ }^{1}$ ), nachher wurde er gerade so wie Cornelius Dexter Procurator von Asia. Der Beginn seiner Carrière fällt in die Zeit, als Cornelius Re[pentinus] die Garde befehligte, d. i. zwischen 158 und $161^{2}$ ); so kann ex frühestens unter Marcus und Verus in Ägypten seines Amtes gewaltet haben.

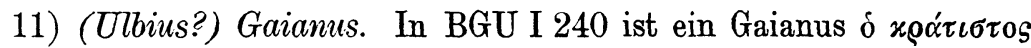

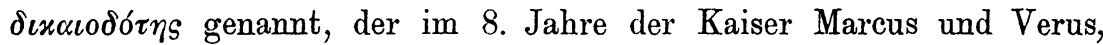
d. i. 167/8, oder wenig später im Amte war. P. Meyer, Herm. XXXII 226, 2 setzt ihn mit Ulb(ius) Gaianus gleich, der als Praefectus vehiculorum durch zwei gleichlautende Weihinschriften (CIL. III 4802. V 5797) bekannt ist. Dann wäre seine Laufbahn ähnlich wie bei Baebius Iuncinus.

12) Maecianus. An dem Aufstand des Avidius Cassius im J. 175 beteiligten sich sowohl der damalige Präfekt von Ägypten, C. Flavius Calvisius Statianus, als auch Maecianus, cui Alexandria erat commissa (Hist. Aug. Marc. 25, 4. Avid. Cass. 7, 4; an der ersten Stelle wird er - ohne Zweifel irrtümlich - als Sohn des Cassius bezeichnet); jener wurde später verbannt, dieser sogleich von dem kaisertreuen Heer getötet. Dafs der zitierte Ausdruck besage, Maecianus sei iuridicus Alexandreae gewesen, ist nicht einmal völlig sicher. ${ }^{3}$ ) Keinesfalls ist er der Präfekt von Ägypten [L. Vol]usius Maecianus, der BGU II 613 genannt ist; denn dieser war, wie wir jetzt endlich wissen, im J. 161 Präfekt. $\left.{ }^{4}\right)$

13) C. Caecilius Salvianus war Juridicus in Ägypten zu der Zeit, als Avidius Cassius seinen Aufstand erhob oder unmittelbar danach. Als der an dieser Verschwörung beteiligte Präfekt von Ägypten, C. Flavius Calvisius Statianus, seines Amtes enthoben und verbannt worden war, trat der Iuridicus Salvianus provisorisch an seine Stelle; dies

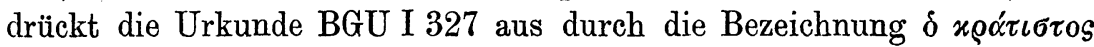

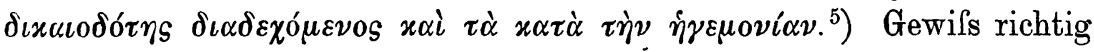

1) Mommsen ergänzt ab epistulis [Latinis adiutori]; Hirschfelds (Verw. -G. I 34,1$)$ Vermutung, er sei Sekretär des Cäsars M. Aurelius gewesen, ist kaum richtig, da zu dieser Zeit Pius nicht mehr gelebt haben dürfte.

2) S. Pauly-Wissowa s. v. Cornelius Repentinus.

3) Er könnte z. B. auch procurator ad dioecesin Alexandreae gewesen sein.

4) Genf. Pap. 35; vgl. Jahreshefte des österr. arch. Inst. III Beibl. 221. Arch.epigr. Mitt. XIX $151 \mathrm{ff}$.

ə) Vgl. Arch.- epigr. Mitt. a. a. 0 . 
hat P. Meyer ${ }^{1}$ ) den Namensrest ..... nus in P. Lond. II 173, nr. 1 y8 ebenfalls auf Salvianus bezogen; vielleicht erklärt sich so, dals die Petition an ihn statt an den Präfekten gerichtet ist. Man könnte

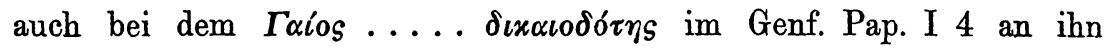
denken. ${ }^{2}$ ) Vgl. auch Nr. 10. Vor Ende August 176 war er schon durch T. Pactumeius Magnus in der Statthalterschaft ersetzt, P. Fay. 159; ob er dann noch Juridicus geblieben ist, wissen wir nicht.

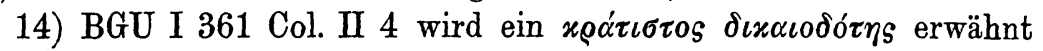
in einem Fragment aus den Tagebüchern des Strategen Apollonius im J. 184. ${ }^{3}$ ) Da keiner der uns Bekannten für dieses Jahr bezeugt ist, können wir diesem Iuridicus vorläufig keinen Namen geben.

15) Weder dem Namen noch genau der Zeit ${ }^{4}$ ) nach zu bestimmen

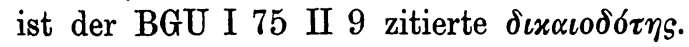

16) Der bisher namenlose iuridicus auf der stadtrömischen Inschrift VI 1638 = Dessau 1331 ist, wie wir jetzt sehen, niemand anders als C. Iulius Priscus, der Bruder des Kaisers Philippus. ${ }^{5}$ ) Aus seinem Cursus honorum ergiebt sich, dafs er, nachdem er [proc(urator)] von Macedonia gewesen war, iu[ridicus Alexandreae] wurde und hier wahrscheinlich gerade so wie Caecilius Salvianus wegen einer Vakanz in der Präfektur Ägyptens auch als provisorischer Statthalter, vice praef(ecti) Aeg[ypti], fungierte. Wohl noch unter Gordian hat er dies Amt verwaltet; denn zu Beginn der Regierung seines Bruders war er Praefectus Mesopotamiae.

17) Der nachdiocletianischen Zeit gehört an Fl(avius) Gennadius, $\mathrm{v}$ (ir) $\mathrm{p}$ (erfectissimus), iuridic(us) Alex(andreae) im J. 350, den wir aus dem von Jouguet a. a. 0. mitgeteilten Papyrus kennen lernen.

Über die Stellung dieser Beamten in der ritterlichen Carrière lärst sich, da wir nur von ganz wenigen derselben den Cursus honorum kennen, wenig sagen. Die darauf bezüglichen Beobachtungen erschöpfen

1) Das Heerwesen der Ptolemäer und Römer in Ägypten 146.

2) Ist dies richtig, dann bietet auch dieser Papyrus kein Beispiel für die Kompetenz des Juridicus gegenüber den Bewohnern der $\chi$ ó $\alpha$, vgl. Arcbiv 312, 1.

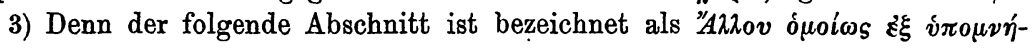

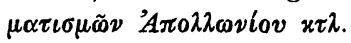

4) Im Nachtrag zum I. Band wird der Papyrus dem 2. Jahrh. n. Chr. zugewiesen.

5) Diese schon von Waddington $\mathrm{zu} \mathrm{nr} .2077 \mathrm{f}$. seines Inschriftenwerkes geäufserte Vermutung wird jetzt durch eine neugefundene Inschrift aus Suhba im Haurân (Philippopolis) bestätigt, vgl. v. Domaszewski, Rhein. Mus. 1899, 159 f. 
sich damit, dafs wir zwei Fälle (nr. 5 und 10) kennen, in welchen der Juridicus von Ägypten Prokurator von Asia und einen (nr. 16), in welchem er Präfekt von Mesopotamia wird; die Ernennung zum Juridicus erfolgt von der Stellung eines Praefectus vehiculorum (nr. 3 und vielleicht auch nr. 11), eines procurator Neaspoleos et mausolei Alexandreae (nr. 5), eines ab epistulis [Latinis adiutor?] (nr. 10) und eines Procurators von Macedonia (nr. 16). In zwei Fällen (nr. 13 und 16) sehen wir, dals der Juridicus zur Stellvertretung des Präfekten berufen ist. - Das Prädikat, das dem Juridicus in ägyptischen Urkunden (seit

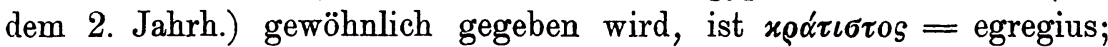

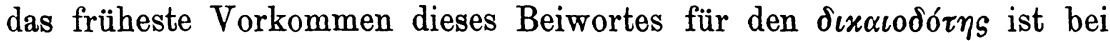
Claudius Neocydes (nr. 6) belegt: P. Lond. II 152, nr. 196 aus dem J. 147. Dafs Flavius Gennadius vir perfectissimus heifst, entspricht der Titulatur im 4. Jahrh., wo dieses Prädikat an unterscheidender Kraft viel eingebülst hat. ${ }^{1}$ )

Wien.

Arthar Stein.

1) Vgl. Hirschfeld Sitzungsber. der Berl. Akad. 1901, $589 \mathrm{ff}$. 